streams of more than $20 \mathrm{~cm}$. from jets used, and it therefore seems that no great increase in efficiency would result from making the apparatus any taller. The optimum diameter of the jet appears to be about $0.4 \mathrm{~mm}$.

The dialysis time for a 0.5 saturated ammonium sulphate solution under these conditions is about thirty hours, and the final concentration inside the sae is approximately $1 / 500$ of the initial concentration, that is, of the order of $0.1 \mathrm{mgm}$. nitrogen/c.c. This dilution corresponds to $1 / 12$ of the concentration that would occur if all the salt in the sac were to be evenly distributed throughout the whole volume of the dialysate.

To avoid salt contamination of the water in the outside vessel, the apparatus is set up as follows. The dialysis sac is placed inside vessel $B$, and $B$ is then lowered into $A$, which already contains the approximately correct volume of water. When the inside and outside levels are the same, the syphon is filled and dropped into place.

The term 'gravity dialyser' is suggested for the apparatus.

University of London,

J. S. FALCONER.

King's College,

Strand, W.C.2.

June 5 .

${ }^{1}$ Kunitz, M., and Simms, H. S., J. Gen. Physiol., 11, 641 (1928).

\title{
A Speculation on the Bactericidal Activity of certain Tellurium Compounds
}

THE intense bactericidal activity of cyclotelluropentane-3 : 5-dione (I) and some of its homologues was reported by Morgan and his collaborators ${ }^{1-4}$. This property is shared only to a limited extent by other tellurium compounds; it is not due to the lability of tellurium in this ring, since conversion of (I) into its equally labile dioxime causes a marked drop in bactericidal power (see table). The theory of substrate competition ${ }^{5}$ provides a rational explanation of the activity of this group of compounds. The formula of one of the highly active members, $2: 4$ dimethyl-cyclotelluropentane-3 : 5 -dione (II), bears a striking resemblance to that of pyridoxine (III), which is known to be a growth-factor for many species of micro-organisms ${ }^{6-8}$, and it seems to us possible that the relation between the two substances may be similar to that between $p$-amino-benzoic acid and sulphanilamide $\theta, 10$.

In the present circumstances, we are unable to test this hypothesis experimentally ; but the following facts may be adduced in its support, the data on $B$. coli communis being drawn from the table. Similar results are available ${ }^{2}$ from experiments on $B$. typhosus, Stapl. pyogenes aureus and Strep. homolyticus.

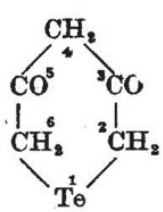

(I)

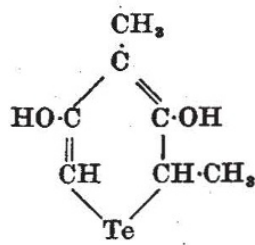

(II)

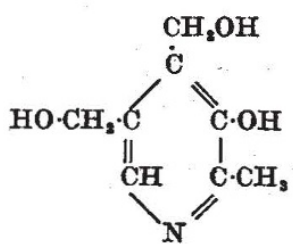

(III) (i) The bactericidal effect requires the presence of an enolic hydroxyl group in the 3-position of the cyclotelluropentane-3 : 5-dione ring. When enolization is previented (the dioxime) or inhibited (the 4:4diethyl compound) the effect is less marked. A hydroxyl occurs in the corresponding position of the pyridoxine molecule.

(ii) The bactericidal effect is sensitive to the nature and position of substituents in the cyclotelluropentane-3:5-dione ring. The $1: 1$-dihalides are inactive and the strongly polar 4-chloro-compound has only very weak activity. Unsubstituted cyclotelluropentane-3 : 5-dione is moderately effective, but the introduction of small alkyl groups (methyl or ethyl) in the 2-position greatly enhances the bactericidal power; larger alkyl groups (propyl, butyl or amyl) are less effective. A methyl group in the 2-position characterizes the pyridoxine molecule.

Pyridoxine bears an alkyl substituent in the 4-position, and 4-alkylated derivatives of cyclotelluropentane-3:5-dione are considerably more active than the parent substance. The $2: 4$-dimethyl compound is second equal in activity in the series which was tested.

If the arrangement $\mathrm{N} \cdot \mathrm{C}\left(\mathrm{CH}_{3}\right) \cdot \mathrm{C}(\mathrm{OH}) \cdot \mathrm{C}$ may be regarded as of fundamental bacteriological significance in the pyridoxine structure, it should be noted that the most active tellurium derivatives tested, $2: 6$ dimethyl and $2: 6$-diethyl cyclotelluropentane-3: 5 dione, contain this arrangement twice, nitrogen being replaced by tellurium.

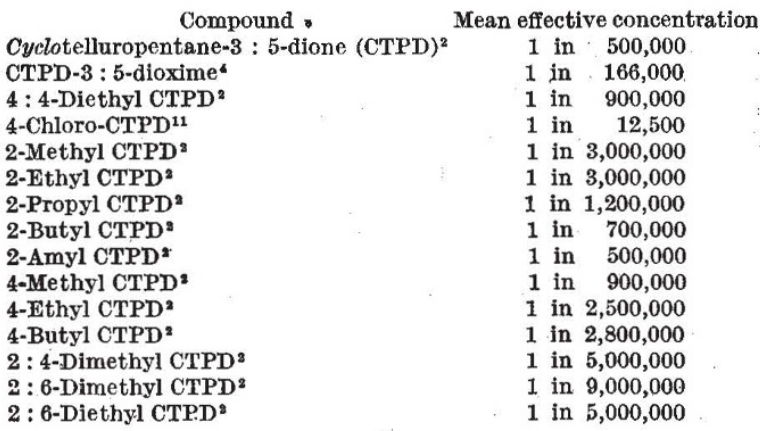

Should our general hypothesis be correct, it seems possible that compounds related to cyclotelluropentane-3 : 5-dione, but containing oxygen or sulphur instead of tellurium, might have correspondingly high bactericidal or bacteriostatic properties without the alarming toxicity which makes cyclotelluropentane$3: 5$-dione itself quite impossible for therapeutic use. J, Masson GuLLand. W. V. FARRAR.

Chemistry Department,

University College, Nottingham. May 7.

${ }^{1}$ Morgan, Cooper and Burtt, Biochem. J., 17, 30 (1923).

"Morgan, Cooper and Burtt, Biochem. J., 18, 190 (1924).

s Morgan, Cooper and Corby, J. Soc. Chem. Ind., 43, $304 T(1924)$

- Morgan, Cooper and Rawson, J. Soc. Chem. Ind., 45, 106T (1926).

s Fildes, Lancet, 288, 955 (1940).

- Möller, Z. physiol. Chem., 254, 285 (1938).

'McIlwain, Brit. J. Expt. Path., 21, 25 (1940).

- Ann. Rev. Biochem., 9, 400 (1940); 10, 352 (1941); 11, 326 (1942); 12, 554, $557(1943)$

- Woods, Brit. J. Expt. Path., 21, 74 (1940).

${ }^{10}$ Ann. Rev. Biochem., 12, 561 (1943).

${ }^{11}$ Calculated from data of Morgan and Drew, J. Chem. Soc., 121, 922 (1922). 